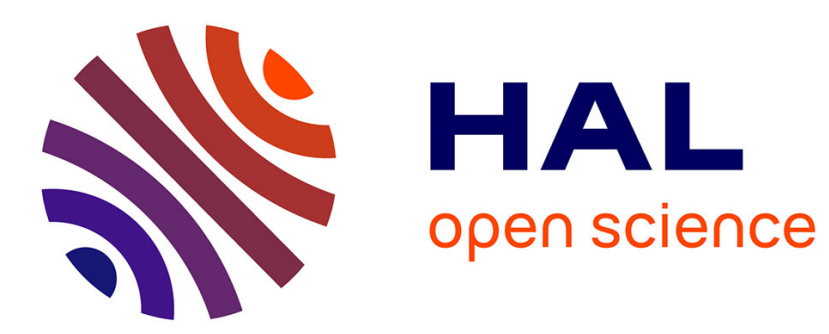

\title{
Steady State Voltammetry of Charge Transfer Processes with Nonunity Electrode Reaction Orders
}

\author{
J. González, E. Laborda, C. Serna, E. Torralba, A. Molina
}

\section{To cite this version:}

J. González, E. Laborda, C. Serna, E. Torralba, A. Molina. Steady State Voltammetry of Charge Transfer Processes with Nonunity Electrode Reaction Orders. Journal of Electroanalytical Chemistry, 2021, 896, pp.115206. 10.1016/j.jelechem.2021.115206 . hal-03363822

\section{HAL Id: hal-03363822 \\ https://hal.science/hal-03363822}

Submitted on 4 Oct 2021

HAL is a multi-disciplinary open access archive for the deposit and dissemination of scientific research documents, whether they are published or not. The documents may come from teaching and research institutions in France or abroad, or from public or private research centers.
L'archive ouverte pluridisciplinaire HAL, est destinée au dépôt et à la diffusion de documents scientifiques de niveau recherche, publiés ou non, émanant des établissements d'enseignement et de recherche français ou étrangers, des laboratoires publics ou privés. 


\title{
Steady State Voltammetry of Charge Transfer Processes with Nonunity Electrode Reaction Orders
}

\author{
J. González, E. Laborda, C. Serna, E. Torralba, A. Molina*
}

Departamento de Química Física, Facultad de Química, Regional Campus of International Excellence "Campus Mare Nostrum”, Universidad de Murcia, 30100 Murcia, Spain

\footnotetext{
* Corresponding author:

Tel: +34868 887524

Fax: +34868884148

Email: amolina@um.es
}

This article is dedicated to our dear friend Juan on his $70^{\text {th }}$ birthday. 


\begin{abstract}
Relevant electrochemical processes present rate equations with non-unity reaction orders. For such reactions, an analytical treatment is developed for the stationary voltammetric response and the surface concentrations at the rotating disc electrode and at microelectrodes of any shape, as frequently/preferably employed to reveal their electrode kinetics. The expressions deduced are applicable when one or both redox species are initially present and cover any degree of reversibility.

From the general solution obtained, the limit cases of fully reversible and irreversible reactions are derived. By linearizing the current-potential response of the former, the reaction orders can be determined, as well as the value of the reversible half-wave potential that strikingly depends on whether one or both species are initially present in contrast with the case of unity orders. For irreversible processes, the linearization of the complete current-potential response is also possible and it enables us to extract the reaction order and the half-wave potential. An expression for the latter is given as a function of the heterogeneous rate constant and the mass transport coefficient. Additional protocols of kinetic analysis are discussed on the basis of Tafel and Koutecký-Levich-like plots.
\end{abstract}

Keywords: Nonunity reaction orders; Analytical theory; Steady state voltammetry; Electrode kinetics; Electrocatalysis 


\section{Introduction}

There exists a number of complex electrochemical processes that show nonunity reaction orders. Some examples that have been postulated include the reaction order of $\mathrm{O}_{2}$ and $\mathrm{H}^{+}$in the oxygen reduction reaction (ORR) at the rotating disc electrode (RDE) [1], the oxidation of thiolates and reduction of disulfides [2], the oxidation of bromide [3], the hydrogen and chlorine evolution reactions [4] (see also Supporting Information, section S4), ... Also, a variety of reversible electron transfers with nonunity stoichiometry have been reported (see [5-9] and references therein), which could show kinetic limitations when using fast rotation speeds at the RDE or microelectrodes.

For the processes above mentioned under steady state conditions (that is, when RDE or ultramicroelectrodes with any potential waveform are used), the following relationship has been proposed between the observed rate of reaction and the surface concentrations of electroactive species $\mathrm{O}$ and $\mathrm{R}, c_{\mathrm{i}}^{\mathrm{s}}(\mathrm{i}=\mathrm{O}, \mathrm{R})[1-4]$ :

$$
\mathrm{v}=k_{f}\left(c_{\mathrm{O}}^{\mathrm{s}}\right)^{v_{\mathrm{O}}}-k_{b}\left(c_{\mathrm{R}}^{\mathrm{s}}\right)^{v_{\mathrm{R}}}
$$

where $v_{\mathrm{O}}$ and $v_{\mathrm{R}}$ are the cathodic and anodic reaction orders, and $k_{f}$ and $k_{b}$ the apparent ${ }^{1}$ potential-dependent heterogeneous rate constants. Eqn. (1) is a rate equation that, in a simplistic yet insightful way, could be ascribed to the 'operational' reaction

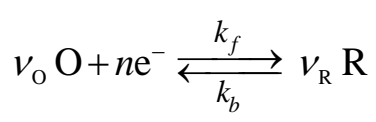

with the rate constants being given by the Butler-Volmer formalism [10],

$$
\left.\begin{array}{l}
k_{f}=k^{0^{\prime}}\left(c^{0}\right)^{1-v_{\mathrm{O}}} e^{-\alpha \eta} \\
k_{b}=k^{0^{\prime}}\left(c^{0}\right)^{1-v_{\mathrm{R}}} e^{(1-\alpha) \eta}
\end{array}\right\} \quad \frac{k_{b}}{k_{f}}=e^{\eta}\left(c^{0}\right)^{v_{\mathrm{O}}-v_{\mathrm{R}}}
$$

where

$$
\eta=\frac{n F}{R T}\left(E-E^{0^{\prime}}\right)
$$

$k^{0^{\prime}}, \alpha$ and $E^{0^{\prime}}$ refer to apparent heterogeneous rate constant, charge transfer coefficient and formal potential, respectively, and $c^{0}$ to the standard concentration, which ensures the dimensional correctness (usually, $c^{0}=1 \mathrm{~mol} \mathrm{dm}^{-3}$ ) [10]. Considering reaction (I) will enable us to develop a general theoretical framework from which the more realistic cases of fully reversible [5-9] and irreversible [1,4] processes will be easily derived, and procedures will be established for the identification of the reaction orders and kinetic parameters. This is very valuable to get

\footnotetext{
${ }^{1}$ It should be borne in mind that the true nature of processes underlying rate expressions like Eqn. (1) are likely complex (see Supporting Information).
} 
fruitful insights into the process, for example, assisting the benchmarking of the electrocatalytic performance of electrode materials, as well as elucidating of mechanistic nuances.

In this work, a detailed theoretical study of an electrochemical process following Eqn. (1) and Scheme (I) will be carried out. A general expression for the surface concentrations and the current-potential response will be deduced for any degree of reversibility and any cathodic and anodic reaction orders. The expressions are applicable to the rotating disc electrode (RDE) and to microelectrodes of any geometry. Also, it is considered that both the oxidized and reduced species may be initially present in solution. From the general theory developed, the particular expressions for the current-potential response and the half-wave potential of the fully reversible and fully irreversible regimes will be derived. In the reversible limit, the theoretical solutions coincide with those obtained for transient [9] and stationary [11] conditions. It is also pointed out that, in contrast with unity reaction orders, the reversible half-wave potential is dependent on whether one or both species are initially present. For sufficiently small $k^{0^{\prime}}$ values, the fully irreversible regime is reached; this is found to occur 'earlier' (i.e., at larger $k^{0^{\prime}}$ ) as $v_{0}$ or $v_{\mathrm{R}}$ are greater. For the quantitative analysis, various protocols are discussed based on the linearization of the complete I-E response, and on the generalizations of the Tafel and the Koutecký-Levich plots to high orders. 


\section{Theory}

Under steady state mass transport conditions in the absence of migration and convection, the following boundary value problem (bvp) must be solved to describe the voltammetric response of Scheme (I):

$$
\left.\begin{array}{l}
\nabla_{\mathrm{G}}^{2} c_{\mathrm{O}}=0 \\
\nabla_{\mathrm{G}}^{2} c_{\mathrm{R}}=0
\end{array}\right\}
$$

$q \rightarrow \infty$

$$
c_{\mathrm{O}}(q)=c_{\mathrm{O}}^{*}, c_{\mathrm{R}}(q)=c_{\mathrm{R}}^{*}
$$

$q=q_{S}$

$$
\begin{aligned}
& \frac{D_{\mathrm{O}}}{v_{\mathrm{O}}}\left(\frac{\partial c_{\mathrm{O}}}{\partial q_{N}}\right)_{q_{N}=q_{S}}=-\frac{D_{\mathrm{R}}}{v_{\mathrm{R}}}\left(\frac{\partial c_{\mathrm{R}}}{\partial q_{N}}\right)_{q_{N}=q_{S}} \\
& \frac{D_{\mathrm{O}}}{v_{\mathrm{O}}}\left(\frac{\partial c_{\mathrm{O}}}{\partial q_{N}}\right)_{q_{N}=q_{S}}=k_{f}\left(c_{\mathrm{O}}^{s}\right)^{v_{\mathrm{O}}}-k_{b}\left(c_{\mathrm{R}}^{s}\right)^{v_{\mathrm{R}}}
\end{aligned}
$$

where $c_{\mathrm{i}}^{*}$ and $c_{\mathrm{i}}(\mathrm{i}=\mathrm{O}, \mathrm{R})$ refer to the concentrations of the redox species at the bulk of the solution and to the concentration profile which depends on the spatial coordinates $q$, respectively, and $\nabla_{G}^{2}$ to the stationary diffusion operator for the microelectrode geometry (see Table S1 in the Supporting Information). The current response, when a constant or time variable potential is applied to an electrode of an arbitrary geometry $(\mathrm{G})$ of area $\mathrm{A}$, being both $\mathrm{O}$ and $\mathrm{R}$ solution soluble, can be written in a general form as:

$$
\frac{I}{n F A}=\frac{D_{\mathrm{O}}}{v_{\mathrm{O}}}\left(\frac{\partial c_{\mathrm{O}}}{\partial q_{N}}\right)_{q_{N}=q_{S}}=-\frac{D_{\mathrm{R}}}{v_{\mathrm{R}}}\left(\frac{\partial c_{\mathrm{R}}}{\partial q_{N}}\right)_{q_{N}=q_{S}}
$$

where $q_{\mathrm{N}}$ refers to the spatial coordinate $(q)$ normal to the electrode surface, and $q_{\mathrm{S}}$ to its value at the surface of the electrode.

When the RDE is used, convection plays a fundamental role. In this case, another stationary behaviour appears and Eqn. (4) should be replaced by:

$$
\left.\begin{array}{c}
D_{\mathrm{O}} \frac{\partial^{2} c_{\mathrm{O}}}{\partial z^{2}}-v_{\mathrm{z}} \frac{\partial c_{\mathrm{O}}}{\partial z}=0 \\
D_{\mathrm{R}} \frac{\partial^{2} c_{\mathrm{R}}}{\partial z^{2}}-v_{\mathrm{z}} \frac{\partial c_{\mathrm{R}}}{\partial z}=0
\end{array}\right\}
$$

with $v_{z}$ being the axial component of the velocity that is given by [12]:

$$
v_{z}=-0.51023 \zeta^{-1 / 2} \omega^{3 / 2} z^{2}+0.33333 \zeta^{-1} \omega^{2} z^{3}+\ldots
$$


where $\zeta$ is the kinematic viscosity of the electrolyte and $\omega$ the angular velocity of the electrode. Under usual conditions, the axial component of the velocity is approximated to the first term on the right hand side [13].

For all the above conditions, it can be easily demonstrated that, whatever the reversibility degree of the process, the stationary concentration profiles can be written as $[11,14,15]$ :

$$
\left.\begin{array}{l}
c_{\mathrm{O}}(q)=c_{\mathrm{O}}^{*}+\left(c_{\mathrm{O}}^{\mathrm{s}}-c_{\mathrm{O}}^{*}\right) H_{\mathrm{G}, \mathrm{O}}(q) \\
c_{\mathrm{R}}(q)=c_{\mathrm{R}}^{*}+\left(c_{\mathrm{R}}^{\mathrm{s}}-c_{\mathrm{R}}^{*}\right) H_{\mathrm{G}, \mathrm{R}}(q)
\end{array}\right\}
$$

where $H_{\mathrm{G}, \mathrm{i}}(q)$ is a continuous function ${ }^{2}$ that depends on the set of spatial coordinates $(q)$ of the specific electrode geometry $\mathrm{G}$ (but not on the applied potential), so that the potential-dependence in (11) is restricted to the surface concentrations (see below), that is, to the terms $\left(c_{\mathrm{i}}^{\mathrm{s}}-c_{\mathrm{i}}^{*}\right)$ ( $\mathrm{i}=\mathrm{O}$, R). It can be easily proven that, independently of the electrode geometry, function $H_{G}(q)$ is the same as for the case $v_{O}=1, v_{R}=1[11]$, referred to as case 1:1 hereafter.

From Eqns. (8) and (11) it follows that the flux of redox species $i$ at the electrode surface can be expressed as:

$$
\frac{I}{n F A}=\frac{D_{\mathrm{O}}}{v_{\mathrm{O}}}\left(\frac{c_{\mathrm{O}}^{*}-c_{\mathrm{O}}^{s}}{\delta_{\mathrm{O}}}\right)=-\frac{D_{\mathrm{R}}}{v_{\mathrm{R}}}\left(\frac{c_{\mathrm{R}}^{*}-c_{\mathrm{R}}^{s}}{\delta_{\mathrm{R}}}\right)
$$

with $\delta_{\mathrm{i}}(\mathrm{i}=\mathrm{O}, \mathrm{R})$ being the stationary thickness of the linear diffusion layer for the experimental conditions (i.e., electrode geometry or mass transport mode) considered, defined as [15]:

$$
\delta_{\mathrm{i}}=\frac{1}{\left(\frac{\partial H_{\mathrm{G}, \mathrm{i}}(q)}{\partial q_{\mathrm{N}}}\right)_{q_{\mathrm{N}}=q_{\mathrm{S}}}} \quad(\mathrm{i}=\mathrm{O}, \mathrm{R})
$$

Eqn. (13) is applicable to one-dimensional geometry systems (spherical and cylindrical microelectrodes) and to RDE. For two-dimensional (disc and band microelectrodes) or more complex geometries, electrode surface averaged or heuristic expressions of $\delta_{\mathrm{i}}$ must be employed (see Table S2).

It is possible to re-write Eqn. (12) in terms of the so-called mass transport coefficient, defined as:

$$
m_{\mathrm{i}}=\frac{D_{\mathrm{i}}}{\delta_{\mathrm{i}}} \quad(\mathrm{i}=\mathrm{O}, \mathrm{R})
$$

such that Eqn. (12) can be re-written as

\footnotetext{
${ }^{2}$ An analytical equation for function $H_{\mathrm{G}, \mathrm{i}}(q)$ has only been obtained for one-dimensional systems. For example for spherical electrodes $H_{\text {sphe, }}(r)=r_{0} / r$.
} 


$$
\frac{I}{n F A}=C_{\mathrm{O}}^{*}-C_{\mathrm{O}}^{s}=-\left(C_{\mathrm{R}}^{*}-C_{\mathrm{R}}^{s}\right)
$$

where

$$
\left.\begin{array}{ll}
C_{\mathrm{O}}^{\mathrm{s}}=c_{\mathrm{O}}^{\mathrm{s}} \frac{m_{\mathrm{O}}}{v_{\mathrm{O}}} ; & C_{\mathrm{O}}^{*}=c_{\mathrm{O}}^{*} \frac{m_{\mathrm{O}}}{v_{\mathrm{O}}} \\
C_{\mathrm{R}}^{\mathrm{s}}=c_{\mathrm{R}}^{\mathrm{s}} \frac{m_{\mathrm{R}}}{v_{\mathrm{R}}} ; & C_{\mathrm{R}}^{*}=c_{\mathrm{R}}^{*} \frac{m_{\mathrm{R}}}{v_{\mathrm{R}}}
\end{array}\right\}
$$

Expressions for the mass transfer coefficient $m_{\mathrm{i}}$ are dependent on the microelectrode geometry or mass transport conditions. Thus, for example, $m_{i}=0.62 D_{i}^{2 / 3} \omega^{1 / 2} \zeta^{-1 / 6}$ for the RDE and $m_{i}=\frac{4}{\pi} \frac{D_{\mathrm{i}}}{r_{\mathrm{s}}}$ for a disc microelectrode of radius $r_{\mathrm{s}}$. The expressions of $m_{\mathrm{i}}$ for a wide variety of microelectrodes are given in Table S2 of the Supporting Information.

From Eqn. (15), the following relationship is immediately deduced:

$$
C_{\mathrm{R}}^{s}+C_{\mathrm{O}}^{s}=C_{\mathrm{R}}^{*}+C_{\mathrm{O}}^{*}
$$

By combining Eqns. (7) and (15)-(17), the following general relationships for $C_{\mathrm{O}}^{\mathrm{s}}$ and $C_{\mathrm{R}}^{\mathrm{s}}$ are obtained:

$$
\begin{aligned}
& K_{f}\left(\frac{v_{\mathrm{O}}}{m_{\mathrm{O}}}\right)^{v_{\mathrm{O}}-1}\left(C_{\mathrm{O}}^{s}\right)^{v_{\mathrm{O}}}-K_{b}\left(\frac{v_{\mathrm{R}}}{m_{\mathrm{R}}}\right)^{v_{\mathrm{R}}-1}\left(C_{\mathrm{R}}^{*}+C_{\mathrm{O}}^{*}-C_{\mathrm{O}}^{s}\right)^{v_{\mathrm{R}}}-\left(C_{\mathrm{O}}^{*}-C_{\mathrm{O}}^{s}\right)=0 \\
& K_{f}\left(\frac{v_{\mathrm{O}}}{m_{\mathrm{O}}}\right)^{v_{\mathrm{O}}-1}\left(C_{\mathrm{R}}^{*}+C_{\mathrm{O}}^{*}-C_{\mathrm{R}}^{s}\right)^{v_{\mathrm{O}}}-K_{b}\left(\frac{v_{\mathrm{R}}}{m_{\mathrm{R}}}\right)^{v_{\mathrm{R}}-1}\left(C_{\mathrm{R}}^{s}\right)^{v_{\mathrm{R}}}+\left(C_{\mathrm{R}}^{*}-C_{\mathrm{R}}^{s}\right)=0
\end{aligned}
$$

where

$$
\left.\begin{array}{l}
K_{f}=k_{f} \frac{v_{\mathrm{O}}}{m_{\mathrm{O}}} \\
K_{b}=k_{b} \frac{v_{\mathrm{R}}}{m_{\mathrm{R}}}
\end{array}\right\}
$$

Eqns. (18)-(19) allows us to determine the expressions of the surface concentrations of species $\mathrm{O}$ and $\mathrm{R}$ for any reaction orders and reversibility degree of the process. For example, for the more usual cases $v_{0}: 1$ and 1: $v_{\mathrm{R}}$ Eqns. (18)-(19) become:

- Case $v_{0}: 1$,

$$
K_{f}\left(\frac{v_{\mathrm{O}}}{m_{\mathrm{O}}}\right)^{v_{\mathrm{O}}-1}\left(C_{\mathrm{O}}^{s}\right)^{v_{\mathrm{O}}}+C_{\mathrm{O}}^{s}\left(1+K_{b}\right)-C_{\mathrm{O}}^{*}\left(1+K_{b}\right)-K_{b} C_{\mathrm{R}}^{*}=0
$$

- Case $1: v_{\mathrm{R}}$

$$
K_{b}\left(\frac{v_{\mathrm{R}}}{m_{\mathrm{R}}}\right)^{v_{\mathrm{R}}-1}\left(C_{\mathrm{R}}^{s}\right)^{v_{\mathrm{R}}}+C_{\mathrm{R}}^{s}\left(1+K_{f}\right)-C_{\mathrm{R}}^{*}\left(1+K_{f}\right)-K_{f} C_{\mathrm{O}}^{*}=0
$$


Note that, in agreement with Eqns. (21) and (22), the solutions for the surface concentrations of species $\mathrm{O}$ for case $v_{0}: 1$ are formally equivalent to those corresponding to species $\mathrm{R}$ for the case $1: v_{\mathrm{R}}$ by simply changing $K_{f}$ by $K_{b}, v_{\mathrm{O}}$ by $v_{\mathrm{R}}$, and $m_{\mathrm{O}}$ and $C_{\mathrm{O}}^{*}$ by $m_{\mathrm{R}}$ and $C_{\mathrm{R}}^{*}$, respectively.

By solving Eqns. (21)-(22), the explicit expressions of the surface concentrations of both electrolytic species are obtained when both $\mathrm{O}$ and $\mathrm{R}$ are initially present in the electrolytic solution for the orders 2:1, 3:1, 1:2 and 1:3, and also for the well-known case 1:1 (see Eqns. (S1)-(S6) of the Supporting Information). The expressions of the surface concentrations corresponding to the most common case where only oxidised species is initially present are the following:

$-1: 1$ case

$$
\left.\begin{array}{l}
c_{\mathrm{O}}^{s}=c_{\mathrm{O}}^{*} \frac{1+K_{b}}{1+K_{f}+K_{b}} \\
c_{\mathrm{R}}^{s}=c_{\mathrm{O}}^{*} \frac{m_{\mathrm{O}}}{m_{\mathrm{R}}} \frac{K_{f}}{1+K_{f}+K_{b}}
\end{array}\right\}
$$

$-2: 1$ case

$$
\left.\begin{array}{l}
c_{\mathrm{O}}^{s}=\frac{1+K_{b}}{2 K_{f}}\left(\sqrt{1+\frac{4 K_{f} c_{\mathrm{O}}^{*}}{1+K_{b}}}-1\right) \\
c_{\mathrm{R}}^{s}=\frac{1}{2} \frac{m_{\mathrm{O}}}{m_{\mathrm{R}}}\left(c_{\mathrm{O}}^{*}-c_{\mathrm{O}}^{s}\right)
\end{array}\right\}
$$

$-3: 1$ case

$$
\left.\begin{array}{l}
\left.c_{\mathrm{O}}^{s}=2 \sqrt{\frac{1+K_{b}}{3 K_{f}}} \sinh \left(\frac{1}{3} \operatorname{asinh}\left(\frac{3}{2} c_{\mathrm{O}}^{*} \sqrt{\frac{3 K_{f}}{1+K_{b}}}\right)\right)\right) \\
c_{\mathrm{R}}^{s}=\frac{1}{3} \frac{m_{\mathrm{O}}}{m_{\mathrm{R}}}\left(c_{\mathrm{O}}^{*}-c_{\mathrm{O}}^{s}\right)
\end{array}\right\}
$$

- 1:2 case

$$
\left.\begin{array}{l}
c_{\mathrm{O}}^{s}=c_{\mathrm{O}}^{*}-\frac{m_{\mathrm{R}}}{2 m_{\mathrm{O}}} c_{\mathrm{R}}^{s} \\
c_{\mathrm{R}}^{s}=\frac{1+K_{f}}{2 K_{b}}\left(\sqrt{1+\frac{8 K_{b} K_{f} \frac{m_{\mathrm{O}}}{m_{\mathrm{R}}} c_{\mathrm{O}}^{*}}{\left(1+K_{f}\right)^{2}}}-1\right)
\end{array}\right\}
$$

- 1:3 case

$$
\left.\begin{array}{l}
c_{\mathrm{O}}^{s}=c_{\mathrm{O}}^{*}-\frac{m_{\mathrm{R}}}{3 m_{\mathrm{O}}} c_{\mathrm{R}}^{s} \\
c_{\mathrm{R}}^{s}=2 \sqrt{\frac{1+K_{f}}{3 K_{b}}} \sinh \left(\frac{1}{3} \operatorname{asinh}\left(\frac{3 K_{f}}{2\left(1+K_{f}\right)} c_{\mathrm{O}}^{*} 3 \frac{m_{\mathrm{O}}}{m_{\mathrm{R}}} \sqrt{\frac{3 K_{b}}{1+K_{f}}}\right)\right)
\end{array}\right\}
$$


The expressions of $c_{\mathrm{O}}^{s}$ and $c_{\mathrm{R}}^{s}$ for the particular cases of reversible and fully irreversible limiting behaviours are easily obtained by making $k_{f}, k_{b} \rightarrow \infty$ and $k_{b} \rightarrow 0$, respectively, in Eqns. (23)-(27), and are given in Table 1.

The general expression for the current-potential response response (when R is not initially present in solution) can be easily deduced by inserting Eqns. (12) and (14) into Eqn. (7). Thus, under these conditions it is obtained that:

$$
\frac{m_{\mathrm{O}}}{v_{\mathrm{O}}} \frac{I}{I_{1, \mathrm{ss}}^{\text {cat }}}=k_{f}\left(c_{\mathrm{O}}^{*}\right)^{v_{\mathrm{O}}-1}\left(1-\frac{I}{I_{1, \mathrm{ss}}^{\text {cat }}}\right)^{v_{\mathrm{O}}}-k_{b}\left(c_{\mathrm{O}}^{*}\right)^{v_{\mathrm{R}}-1}\left(\frac{m_{\mathrm{O}}}{m_{\mathrm{R}}} \frac{v_{\mathrm{R}}}{v_{\mathrm{O}}} \frac{I}{I_{1, \mathrm{ss}}^{\text {cat }}}\right)^{v_{\mathrm{R}}}
$$

where

$$
\begin{gathered}
\frac{I}{I_{1, \mathrm{ss}}^{\mathrm{cat}}}=1-\left(\frac{c_{\mathrm{O}}^{s}}{c_{\mathrm{O}}^{*}}\right)=\frac{m_{\mathrm{R}}}{m_{\mathrm{O}}} \frac{v_{\mathrm{O}}}{v_{\mathrm{R}}}\left(\frac{c_{\mathrm{R}}^{s}}{c_{\mathrm{O}}^{*}}\right) \\
I_{1, \mathrm{ss}}^{\mathrm{cat}}=\frac{n}{v_{\mathrm{O}}} F A m_{\mathrm{O}} c_{\mathrm{O}}^{*}
\end{gathered}
$$

Eqn. (28) in the more general situation where $c_{\mathrm{R}}^{*} \neq 0$ is given by Eqn. (S7) of the Supporting Information.

\subsection{Reversible and fully irreversible electrode reactions}

The current-potential curves corresponding the reversible [5-9] and irreversible [1,4] limits can be easily deduced by introducing the particular expressions of the surface concentrations of species $\mathrm{O}$ and $\mathrm{R}$ corresponding to these limiting behaviours (see Table 1) into Eqn. (7).

\subsubsection{Linearized reversible response}

For the reversible case, by making $k_{f}, k_{b} \rightarrow \infty$ in Eqn. (28), and taking into account that $k_{b} / k_{f}=e^{\eta}\left(c^{0}\right)^{v_{\mathrm{O}}-v_{\mathrm{R}}}$, the current-potential response can be linearized in the form $\mathrm{E}-\ln (f(\mathrm{I}))$. The general expression obtained is valid independently of the value of $v_{\mathrm{O}}$ and $v_{\mathrm{R}}$. Thus, the linearized response is given by:

$$
E=E_{1 / 2}^{r}+\frac{R T}{n F} \ln \left(2^{v_{\mathrm{O}}-\nu_{\mathrm{R}}}\right)+\frac{R T}{n F} \ln \left(\frac{\left(\frac{I_{1, \mathrm{ss}}^{\mathrm{cat}}-I}{I_{1, \mathrm{ss}}^{\mathrm{cat}}}\right)^{v_{\mathrm{O}}}}{\left(\frac{I}{I_{1, \mathrm{ss}}^{\mathrm{cat}}}\right)^{v_{\mathrm{R}}}}\right)
$$

with

$$
E_{1 / 2}^{r}=E^{0^{\prime}}+\frac{R T}{n F} \ln \left(\left(\frac{m_{\mathrm{R}}}{m_{\mathrm{O}}} \frac{v_{\mathrm{O}}}{v_{\mathrm{R}}}\right)^{v_{\mathrm{R}}}\left(\frac{c_{\mathrm{O}}^{*}}{c^{0}}\right)^{v_{\mathrm{O}}-v_{\mathrm{R}}}\right)+\frac{R T}{n F} \ln \left(2^{v_{\mathrm{R}}-v_{\mathrm{O}}}\right)
$$


Therefore, a plot of the applied potential versus $\ln \left(\left(\left(I_{1, \mathrm{ss}}^{\mathrm{cat}}-I\right) / I_{1, \mathrm{ss}}^{\mathrm{cat}}\right)^{v_{\mathrm{O}}} /\left(I / I_{1, \mathrm{ss}}^{\mathrm{cat}}\right)^{V_{\mathrm{R}}}\right)$ should be linear in agreement with Eqn. (31), with an slope equal to $R T /(n F)$ and an intercept $E_{1 / 2}^{r}+R T /(n F) \ln \left(2^{v_{0}-v_{\mathrm{R}}}\right)$. In contrast with the case $1: 1$, when both species are initially present in solution $\left(c_{\mathrm{R}}^{*} \neq 0\right)$, the reversible half-wave potential does not have the same expression (see Eqn. (S10) of the Supporting Information):

$$
E_{1 / 2}^{r}=E^{0^{\prime}}+\frac{R T}{n F} \ln \left[\left(\frac{m_{R}}{m_{O}} \frac{v_{\mathrm{O}}}{v_{\mathrm{R}}}\right)^{\nu_{\mathrm{R}}}\left(\frac{c_{\mathrm{O}}^{*}}{c^{0}}\right)^{v_{\mathrm{O}}-v_{\mathrm{R}}}\right]+\frac{R T}{n F} \ln \left(2^{\nu_{\mathrm{R}}-v_{\mathrm{O}}}\right)+\frac{R T}{n F} \ln \left(\frac{I_{l, s s}^{\mathrm{cat}}-I_{l, s s}^{\mathrm{an}}}{I_{l, s s}^{\mathrm{cat}}}\right)^{v_{\mathrm{O}}-v_{\mathrm{R}}}
$$

It is important to highlight that Eqns (31)-(33) are valid not only under stationary conditions but also for transient conditions and whatever the electrode geometry (that is, for any shape and size of electrode considered); for example, in the case of a planar electrode the mass transport coefficient is given by $m_{i}=\sqrt{D_{\mathrm{i}} /(\pi t)}$.

\subsubsection{Linearized fully irreversible responses}

For the fully irreversible limit, $k_{b} \rightarrow 0$, the general expression (28) of the currentpotential response becomes into:

$$
I=n F A k_{f}\left(c_{\mathrm{O}}^{*}\right)^{v_{\mathrm{O}}}\left(1-\frac{I}{I_{1, \mathrm{ss}}^{\mathrm{cat}}}\right)^{v_{\mathrm{O}}}
$$

which is obviously independent of the value of coefficient $v_{R}$ and therefore coincident with the case $v_{\mathrm{O}}: 1$ (see below). From Eqn. (34), the following linearized expression is deduced:

$$
E=E_{1 / 2}^{\text {irev,cat }}+\frac{R T}{\alpha n F} \ln \left(2^{1-v_{0}}\right)+\frac{R T}{\alpha n F} \ln \left(\frac{\left(\frac{I_{1, \mathrm{ss}}^{\text {cat }}-I}{I_{1, \mathrm{ss}}^{\text {cat }}}\right)^{v_{\mathrm{O}}}}{\left(\frac{I}{I_{1, \mathrm{ss}}^{\text {cat }}}\right)}\right)
$$

with

$$
E_{1 / 2}^{\text {irrev,cat }}=E^{0^{\prime}}+\frac{R T}{\alpha n F} \ln \left(2^{v_{\mathrm{O}}-1}\right)+\frac{R T}{\alpha n F} \ln \left(\frac{k^{0^{\prime}} v_{\mathrm{O}}}{m_{\mathrm{O}}}\left(\frac{c_{\mathrm{O}}^{*}}{c^{0}}\right)^{v_{\mathrm{O}}-1}\right)
$$

The expression of $E_{1 / 2}^{\mathrm{i} r e v, a n}$ is given by Eqn. (S12) of the Supporting Information. Moreover, contrarily to the reversible case, Eqns. (36) and (SI.12) for the irreversible cathodic and anodic half wave potentials are only totally rigorous under stationary conditions [16]. According to (35), for irreversible processes, a plot of the applied potential versus 
$\ln \left(\left(\left(I_{1, \mathrm{ss}}^{\mathrm{cat}}-I\right) / I_{1, \mathrm{ss}}^{\mathrm{cat}}\right)^{v_{\mathrm{O}}} /\left(I / I_{1, \mathrm{ss}}^{\mathrm{cat}}\right)\right)$ should be linear, with a slope equal to $R T /(\alpha n F)$ and an intercept $E_{1 / 2}^{\text {irrev,cat }}+R T /(\alpha n F) \ln \left(2^{1-v_{0}}\right)$.

By inverting both members, Eqn. (34) can also be written as:

$$
\frac{1}{I}=\frac{1}{I_{k}}\left(\frac{I_{1, \mathrm{ss}}^{\mathrm{cat}}}{I_{1, \mathrm{ss}}^{\mathrm{cat}}-I}\right)^{v_{\mathrm{O}}}
$$

with $I_{\mathrm{k}}$ being the purely kinetic current:

$$
I_{\mathrm{k}}=n F A k_{f}\left(c_{\mathrm{O}}^{*}\right)^{v_{\mathrm{O}}}
$$

Eqn. (37) coincides with Eqn. (14) in [1] and it is a generalized Koutecký-Levich equation for nonunity reaction orders, which for $v_{\mathrm{O}}=1$ becomes into:

$$
\frac{1}{I}=\frac{1}{I_{k}}+\frac{1}{I_{1, \mathrm{ss}}^{\mathrm{cat}}}=\frac{1}{I_{k}}+\frac{\delta_{\mathrm{O}}}{n F A D_{\mathrm{O}} c_{\mathrm{O}}^{*}} \quad\left(\text { for } \mathrm{v}_{\mathrm{O}}=1\right)
$$

Eqns. (34)-(39), contrarily to the reversible case, are only exact under stationary conditions.

Finally, the well-known cathodic Tafel approximation is obtained directly from Eqn. (7) under irreversible cathodic potentials $\left(k_{b} \rightarrow 0\right)$ when diffusion is not effective $\left(c_{\mathrm{O}}^{s} \cong c_{\mathrm{O}}^{*}\right)$. This limit can be also obtained from Eqns. (35)-(36) by making $I<<I_{1, \mathrm{ss}}^{\mathrm{cat}}$ (i.e., at potentials corresponding to the foot of the wave). Thus, the following potential current relationship is obtained,

$$
E=E^{0^{\prime}}+\frac{R T}{\alpha n F} \ln \left(n F A k^{0^{\prime}}\left(c^{0}\right)^{1-v_{\mathrm{O}}}\left(c_{\mathrm{O}}^{*}\right)^{v_{\mathrm{O}}}\right)-\frac{R T}{\alpha n F} \ln (I)
$$


Table 1. Expressions for the surface concentrations of species $\mathrm{O}$ and $\mathrm{R}$ corresponding to reversible and fully irreversible processes

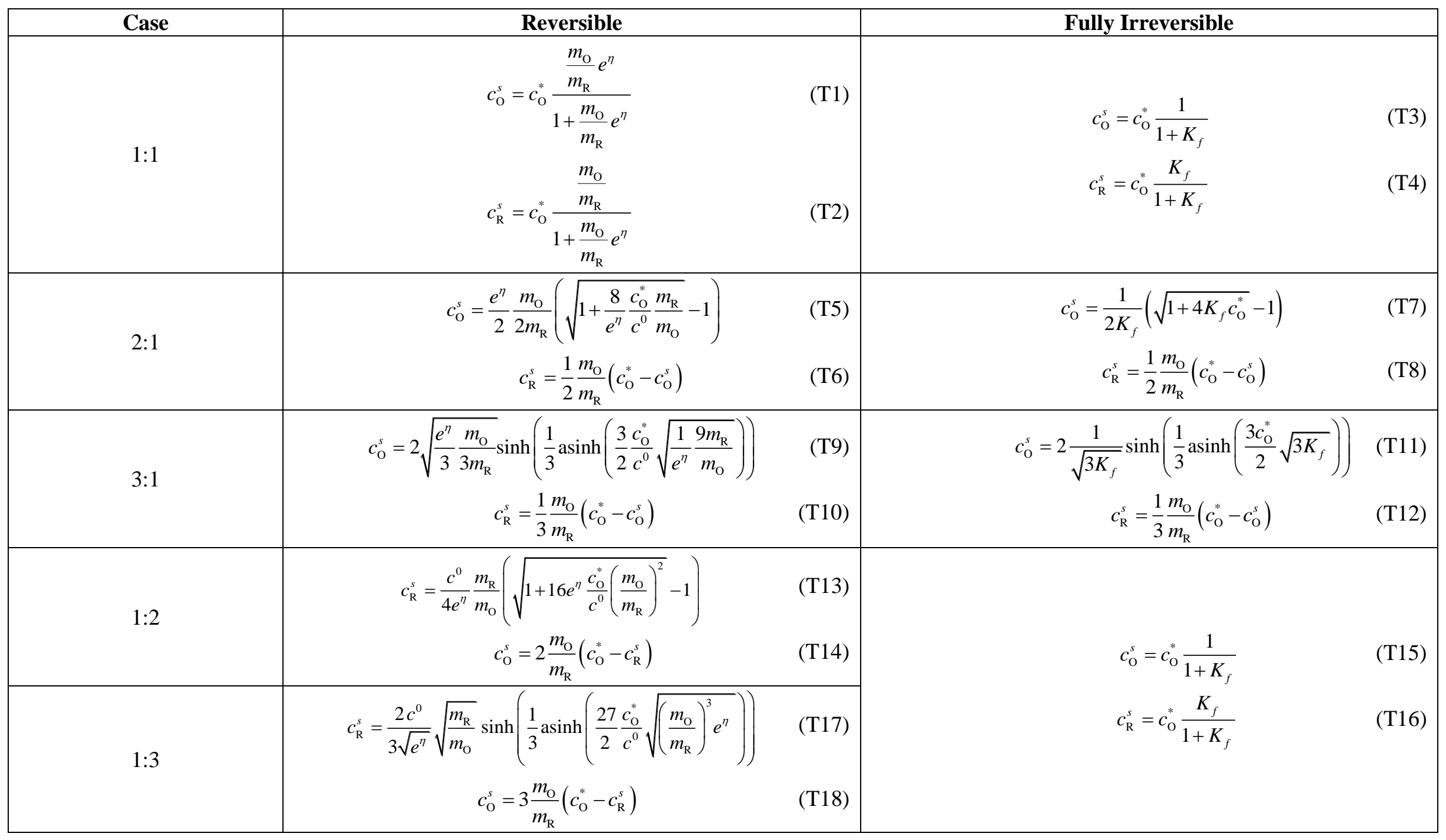




\section{Results and discussion}

Figure 1 illustrates how, independently of the potential-time perturbation applied, there is a univocal current-potential relationship whatever the reaction orders and kinetics when stationary conditions are achieved. For this, the current-potential response of case 2:1 $(n=2)$ with different electrochemical reversibility are compared under transient (spherical microelectrode with $\left.r_{0}=100 \mu \mathrm{m}\right)$ and steady state $\left(r_{0}=1 \mu \mathrm{m}\right)$ conditions when applying two different perturbations: a linear potential waveform (i.e., in linear sweep voltammetry, LSV) or a semicircular waveform, as introduced by Compton et al. [17,18] (see Eqn. (22) in [17]).

As reported for case 1:1 [18], the transient responses in the two techniques differ significantly, with the semi-circular waveform providing larger peaks as a consequence of the extremely fast scan rate around the shift potential. This is particularly remarkable for reversible processes (Fig. 1a) where a very sharp peak is observed.

As can be expected, the differences above mentioned vanish when reaching steady state conditions ( $r_{0}=1 \mu \mathrm{m}$ in Fig. 1), showing the univocal current-potential relationship, independent of the potential-time perturbation applied. Thus, the voltammograms obtained with linear or semicircular (or any other: staircase, sinusoidal, ...) waveform tend to be sigmoidal and overlapping as $r_{0}$ decreases, whatever the electrode kinetics and reaction orders.

$<$ Figure $1>$

Figures 2 and 3 show the stationary current-potential $\left(I / I_{1, \mathrm{ss}}\right)-\left(E-E^{0^{\prime}}\right)$ curves calculated from Eqn. (28) for different reaction orders (Figure 2: $v_{0}=1,2,3$ and $v_{\mathrm{R}}=1$; Figure 3, $\left.v_{0}=1, v_{R}=1,2,3\right)$. These curves have been calculated for different values of the heterogeneous rate constant $\log \left(k^{0^{\prime}} / \mathrm{cm} \mathrm{s}^{-1}\right)=4,2,0-2$ and -4 , at a spherical microelectrode with $\delta_{\mathrm{O}}=\delta_{\mathrm{R}}=r_{0}=1 \mu \mathrm{m}$ and $D_{\mathrm{O}}=D_{\mathrm{R}}=10^{-5} \mathrm{~cm}^{2} \mathrm{~s}^{-1}$ (i.e., $m_{\mathrm{O}}=m_{\mathrm{R}}=0.1 \mathrm{~cm} \mathrm{~s}^{-1}$ ), when only species $\mathrm{O}$ is initially present with $c_{\mathrm{O}}^{*}=10^{-3} \mathrm{M}$. From these curves it can be seen that, for any reaction orders, the I/E response moves towards more negative potentials as $k^{0^{\prime}}$ decreases, with their position varying from the half wave potentials of the reversible process (Eqn. (32)) to that corresponding to a fully irreversible one (Eqn. (36)). Note that the half wave potential, $E_{1 / 2}$, of these curves is more negative or more positive than that corresponding to case $1: 1$, depending on whether $v_{\mathrm{O}}>v_{\mathrm{R}}$ (Figure 2) or $v_{\mathrm{O}}<v_{\mathrm{R}}$ (Figure 3), respectively (see also Figure 4). This fact, along with the identical response of the fully irreversible curves corresponding to cases $1: v_{\mathrm{R}}$ (see curves with $\log \left(k^{0^{\prime}}\right)=-4$ for cases $1: 1,1: 2$ and 1:3 in Figure 3), leads to that the effect of $k^{0^{\prime}}$ on the response is more notorious in cases $v_{0}: 1$ (with $v_{0}>1$ ). This behaviour clearly shows that cases 
2:1 and 3:1 (curves a and $b$ in Figure 2) present greater sensitivity to the charge transfer kinetics than cases 1:2 and 1:3 (curves a and $b$ in Figure 3).

\section{$<$ Figure $2>$ \\ $<$ Figure $3>$}

The plots in Figure 4 correspond to the variation of the half wave potential (referred to the formal potential) with $\log \left(k^{0^{\prime}} / m_{\mathrm{O}}\right)$ for different reaction orders $(1: 2,1: 3,1: 1,2: 1$ and $3: 1)$. These curves show that for large values of $k^{0^{\prime}}, E_{1 / 2}$ tends to the value corresponding to the reversible limit predicted by Eqn. (32). As $k^{0^{\prime}}$ decreases, $E_{1 / 2}$ becomes more negative until reaching the fully irreversible limit where $E_{1 / 2}$ varies linearly with $\log \left(k^{0^{\prime}}\right)$, as indicated in Eqn. (36); note that the greater the $v_{\mathrm{O}}$ or $v_{\mathrm{R}}$ values are, the earlier the irreversible limit is reached (i.e., at larger values of $k^{0^{\prime}}$ ). Also, as has been previously indicated, the curves of all the cases $1: v_{\mathrm{R}}$ (with $v_{\mathrm{R}}=1,2$ and 3) coincide in the irreversible region according with Eqn. (35).

\section{$<$ Figure 4 >}

In Figures 5-7 different approaches for the characterization of the reaction orders and kinetics of reversible and irreversible heterogeneous charge transfers are considered.

According to Eqns. (31) and (35), for fully reversible and irreversible processes the values of the reaction orders can be recognized by identifying the values $v_{\mathrm{O}}$ and $v_{\mathrm{R}}$ that linearize the plot E vs $\ln \left(\left(\left(I_{1, \mathrm{ss}}^{\mathrm{cat}}-I\right) / I_{1, \mathrm{ss}}^{\text {cat }}\right)^{v_{\mathrm{O}}} /\left(I / I_{1, \mathrm{ss}}^{\text {cat }}\right)^{v_{\mathrm{R}}}\right)$, as shown in Figure 5 for cases 2:1 and 1:2 as representative examples. For reversible reactions, the slope of $E$ vs $\ln \left(\left(\left(I_{1, \mathrm{ss}}^{\mathrm{cat}}-I\right) / I_{1, \mathrm{ss}}^{\mathrm{cat}}\right)^{v_{\mathrm{O}}} /\left(I / I_{1, \mathrm{ss}}^{\mathrm{cat}}\right)^{V_{\mathrm{R}}}\right)$ will be $\frac{R T}{n F}$ and the formal potential is accessible from the intercept, which is concentration-dependent for non-unity orders (Eqn. (32)) (see curves with $\log \left(k^{0^{\prime}}\right)=4$ in Figs. 5a (solid lines) and 5b (dashed lines)).

$<$ Figure $5>$

With regard to fully irreversible processes, the slope $\left(=\frac{R T}{\alpha n F}\right)$ of the plot $E v s$ $\ln \left(\left(\left(I_{1, \mathrm{ss}}^{\mathrm{cat}}-I\right) / I_{1, \mathrm{ss}}^{\mathrm{cat}}\right)^{v_{\mathrm{O}}} /\left(I / I_{1, \mathrm{ss}}^{\mathrm{cat}}\right)\right)$ (see curves with $\log \left(k^{0^{\prime}}\right) \leq-2$ in Figs. 5a and 5b) enables us to determine $\alpha$ and, subsequently, the formal potential or the heterogeneous rate constant from the intercept (Eqn. (36)). For this, experiments at different concentrations of reactant can yield more consistent conclusions. Thus, for $v_{0}=1$ the intercept should not depend on $c_{\mathrm{O}}^{*}$; otherwise ( $\left.v_{\mathrm{O}} \neq 1\right)$, the intercept will vary linearly with $\ln \left(c_{\mathrm{O}}^{*}\right)$ with a slope of $\frac{\left(v_{\mathrm{O}}-1\right) R T}{\alpha n F}$ : 


$$
\text { Intercept }=E^{0^{\prime}}+\frac{R T}{\alpha n F} \ln \left(2^{v_{\mathrm{O}}-1}\right)+\frac{R T}{\alpha n F} \ln \left(\frac{k^{0^{\prime}} v_{\mathrm{O}}}{m_{\mathrm{O}}}\right)+\frac{\left(v_{\mathrm{O}}-1\right) R T}{\alpha n F} \ln \left(\frac{c_{\mathrm{O}}^{*}}{c^{0}}\right)
$$

\section{$<$ Figure $6>$}

Complementary to the above, Tafel and Koutecký-Levich-like analyses of the stationary $\left(I / I_{1, s s}\right)-\left(E-E^{0^{\prime}}\right)$ waves of irreversible reactions can be carried out. With respect to the Koutecký-Levich-like analysis, for $v_{0}=1$ the inverse of the current at a given potential (i.e., fixed $I_{\mathrm{k}}$ value) increases linearly with $\delta_{\mathrm{O}}$ (see Eqn. (39)). For $v_{\mathrm{O}} \neq 1$, the plot $\frac{1}{I} v s \delta_{\mathrm{O}}$ is not predicted to be linear, which serves as a diagnosis criterion of a higher kinetic order. In such situation (see Eqn. (34)), the log-log plot $\ln (I) v s \ln \left(1-\frac{I}{I_{\mathrm{l}, \mathrm{ss}}^{\text {cat }}}\right)$ obtained at a given potential with different values of $\delta_{\mathrm{O}}$ (i.e., different RDE speed rotations or different microelectrode size) can be used:

$$
\ln (I)=\ln \left(I_{\mathrm{k}}\right)+v_{\mathrm{O}} \ln \left(1-\frac{I}{I_{\mathrm{l}, \mathrm{ss}}^{\mathrm{cat}}}\right)
$$

in such a way that the value of the slope will correspond directly to the reaction order of the reactant and the value of $k_{\mathrm{f}}$ can be obtained from the intercept (see Eqn. (38)). This is illustrated in Figure 6 for case 2:1. Then, a conventional analysis of $k_{\mathrm{f}}$ at different potentials [13] provides the values of $\alpha$ and $k^{0}$. Note that the fully irreversible regime where the above applies can be approached by enhancing the mass transport conditions (for example, by using smaller electrodes or faster rotation speeds) so that the quantitative analysis is more simple and accurate.

\section{$<$ Figure $7>$}

Regarding the Tafel analysis (see Figure 7), according to Eqn. (40) the intercept of the Tafel plot varies with the reactant concentration whatever the value of $v_{\mathrm{O}}$ :

$$
\text { Intercept }_{\text {Tafel }}=E^{0^{\prime}}+\frac{R T}{\alpha n F} \ln \left(n F A k^{0^{\prime}}\right)+\frac{v_{\mathrm{O}} R T}{\alpha n F} \ln \left(c_{\mathrm{O}}^{*}\right)
$$

so that the slope of Intercept $\mathrm{Tafel} v s \ln \left(c_{\mathrm{O}}^{*}\right)$ enables the determination of $v_{\mathrm{O}}, \alpha$ or $n$, and the values of $E^{0^{\prime}}$ or $k^{0^{\prime}}$ can be extracted from the intercept.

\section{$<$ Figure $8>$}

Finally, the response of high-order reactions in differential techniques is considered in Figure 8. As shown in Fig. 8a, The effect of the electrode kinetics is analogous to that reported for case 1:1 [15] so that the peak becomes smaller and broader and it shifts towards more negative potentials as $k^{0^{\prime}}$ decreases. The variation of the peak potential with the electrode kinetics for 
different pulse amplitudes and reaction orders is shown in Fig. 8b (solid lines), in comparison with the corresponding half-wave potential of the direct-current voltammogram (empty circles). For nonunity orders, in general, the peak potential does not coincide exactly with $E_{1 / 2}$, being slightly more positive or negative depending on the values of $v_{\mathrm{O}}$ and $v_{\mathrm{R}}$; the pulse amplitude also has a scarce effect. The discrepancies are not significant in the irreversible limit $(<10 \mathrm{mV})$ and most notorious in the quasireversible one (up to $30 \mathrm{mV}$ ). Also note that, as mentioned above, the kinetic limitations take place at larger $k^{0^{\prime}}$-values as the reaction orders are higher. 


\section{Conclusions}

Analytical solutions have been obtained for the surface concentrations and currentpotential response of electrode processes that show high reaction orders, specifically, first-, second- or third-order kinetics with respect to the oxidized or the reduced species. The solutions are applicable under steady state conditions reached by using either the rotating disc electrode or microelectrodes of any geometry.

When the electrode kinetics is very fast (reversible processes), the plot $E$ vs $\ln \left(\left(\left(I_{1, \mathrm{ss}}^{\mathrm{cat}}-I\right) / I_{1, \mathrm{ss}}^{\mathrm{cat}}\right)^{v_{\mathrm{O}}} /\left(I / I_{1, \mathrm{ss}}^{\mathrm{cat}}\right)^{v_{\mathrm{R}}}\right)$ is predicted to be linear, whatever the electrode geometry and also under transient conditions. Hence, the reaction orders can be identified as the $v_{\mathrm{O}}$ and $v_{\mathrm{R}}$ values that linearize the experimental plot $E v s \ln \left(\left(\left(I_{1, \mathrm{ss}}^{\mathrm{cat}}-I\right) / I_{1, \mathrm{ss}}^{\mathrm{cat}}\right)^{v_{\mathrm{O}}} /\left(I / I_{1, \mathrm{ss}}^{\mathrm{cat}}\right)^{v_{\mathrm{R}}}\right)$; then, the halfwave potential is obtained from the corresponding intercept. The latter is dependent on the bulk concentrations of the redox species for high orders.

In the case of irreversible reactions, the expression for the half-wave potential has been given and the current-potential response can also be linearized as $E$ vs $\ln \left(\left(\left(I_{1, \mathrm{ss}}^{\mathrm{cat}}-I\right) / I_{1, \mathrm{ss}}^{\mathrm{cat}}\right)^{v_{\mathrm{O}}} /\left(I / I_{1, \mathrm{ss}}^{\mathrm{cat}}\right)\right)$ by adjusting the $v_{\mathrm{O}}$ value; subsequently, the slope of such plot enables the determination of the charge transfer coefficient, while the heterogeneous rate constant can be obtained from the intercept. In this analysis, the whole voltammogram is considered so that it can be expected to provide more representative results than the conventional Tafel plot. A complementary analysis of the complete wave is the generalized Koutecký-Levich plot $\ln (I) v s \ln \left(1-\frac{I}{I_{1, \mathrm{ss}}^{\mathrm{cat}}}\right)$, the slope of which corresponds to the reaction order and the intercept enables the determination of the kinetic parameters.

\section{Acknowledgements}

The authors greatly appreciate the financial support provided by the Fundacion Séneca de la Región de Murcia (Project 19887/GERM/15) and by Ministerio de Economía y Competitividad (PID2019-106097GB-I00). 
Figures
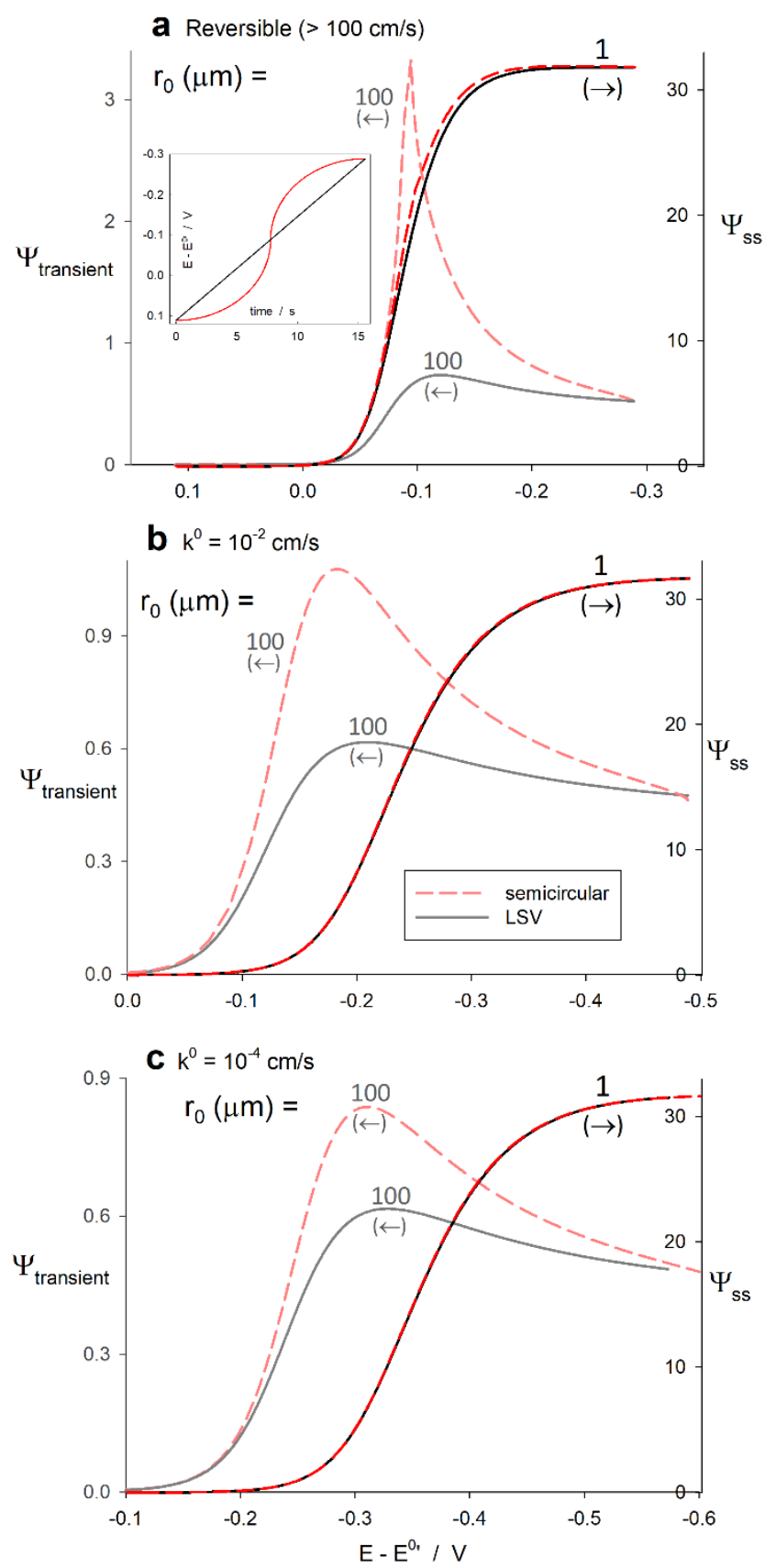

Figure 1. Voltammetry of case 2:1 with $n=2$ at spherical microelectrodes and different $k^{0}$-values (indicated on the graphs) in sweep voltammetry with linear (LSV) and semicircular potential waveforms under transient $\left(r_{0}=100 \mu \mathrm{m}\right)$ and steady state $\left(r_{0}=1 \mu \mathrm{m}\right)$ conditions. $D=10^{-5} \mathrm{~cm} / \mathrm{s}$, $\mathrm{v}=\mathrm{v}_{\mathrm{avg}}=25 \mathrm{mV} / \mathrm{s}, \mathrm{E}_{\text {shift }}=\mathrm{E}_{1 / 2 \text {,rev. }}$. The inset in graph (a) corresponds to the potential waveform in each technique. The arrows indicate the y-axis corresponding to each curve. For the latter, the analytical solutions obtained in Section 2 were employed; the transient responses of the reversible process were obtained with the analytical solution reported in [9] and with numerical simulations for the non-reversible cases [19]. $\Psi=\frac{\mathrm{I}}{F A \mathrm{c}_{\mathrm{O}}^{*} \sqrt{\frac{D F \mathrm{v}}{R T}}}, \alpha=0.5$. 

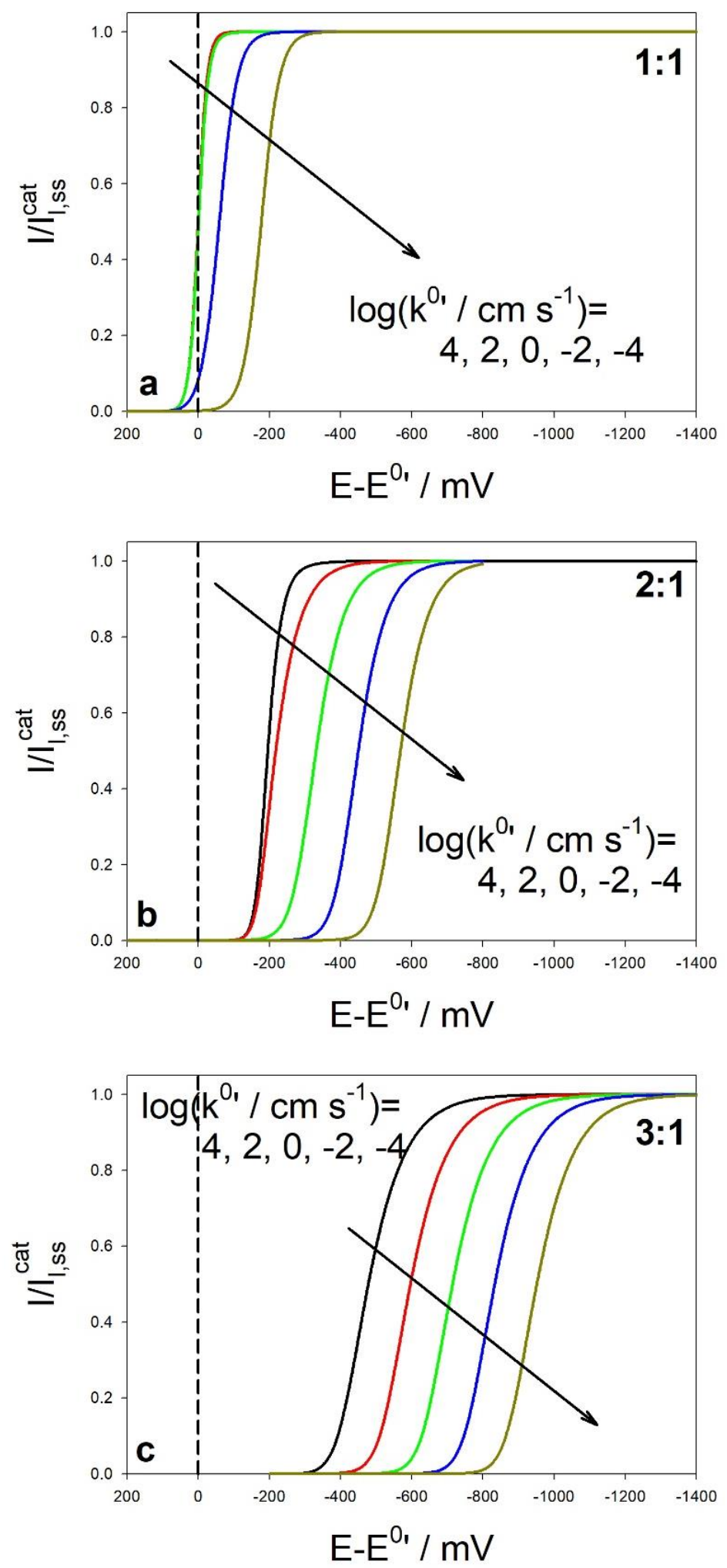

Figure 2. Stationary $\left(I / I_{1, \mathrm{ss}}^{\mathrm{cat}}\right)-\left(E-E^{0^{\prime}}\right)$ curves calculated from Eqn. (28) for cases 1:1, 2:1 and 3:1 with $\delta_{\mathrm{O}}=\delta_{\mathrm{R}}=1 \mu \mathrm{m}$ and $D_{\mathrm{O}}=D_{\mathrm{R}}=10^{-5} \mathrm{~cm}^{2} \mathrm{~s}^{-1}$, calculated for different values of the rate constant (values of $\log \left(k^{0^{\prime}} / \mathrm{cm} \mathrm{s}^{-1}\right)$ indicated on the curves). $\alpha=0.5, n=2, c_{\mathrm{O}}^{*}=10^{-3} \mathrm{M}$. 

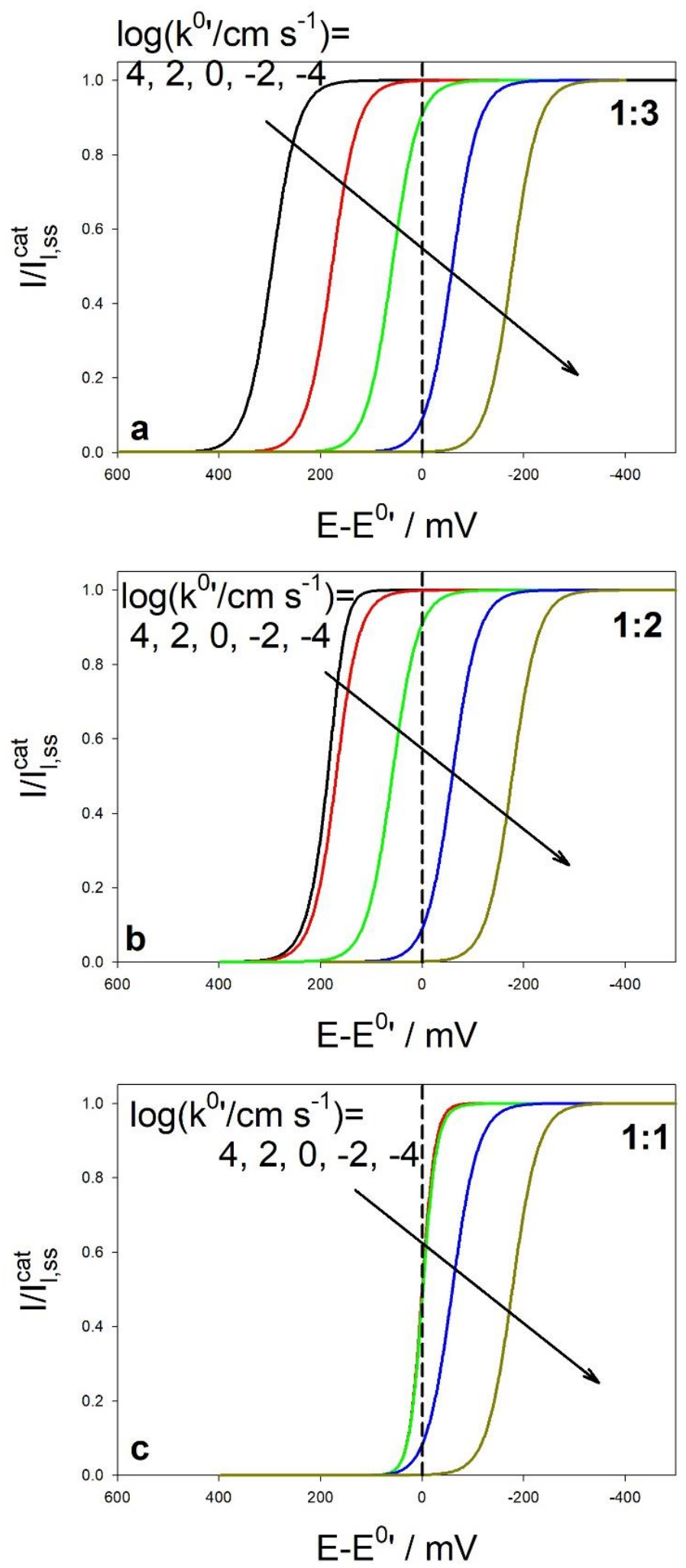

Figure 3. Stationary $\left(I / I_{1, \mathrm{ss}}^{\mathrm{cat}}\right)-\left(E-E^{0^{\prime}}\right)$ curves calculated from Eqn. (28) for cases 1:3, 1:2 and 1:1 corresponding to $\delta_{\mathrm{O}}=\delta_{\mathrm{R}}=1 \mu \mathrm{m}$ and $D_{\mathrm{O}}=D_{\mathrm{R}}=10^{-5} \mathrm{~cm}^{2} \mathrm{~s}^{-1}$, calculated for different values of the rate constant (values of $\log \left(k^{0^{\prime}} / \mathrm{cm} \mathrm{s}^{-1}\right)$ indicated on the curves). $\alpha=0.5, n=2, c_{\mathrm{O}}^{*}=10^{-3}$ M. 


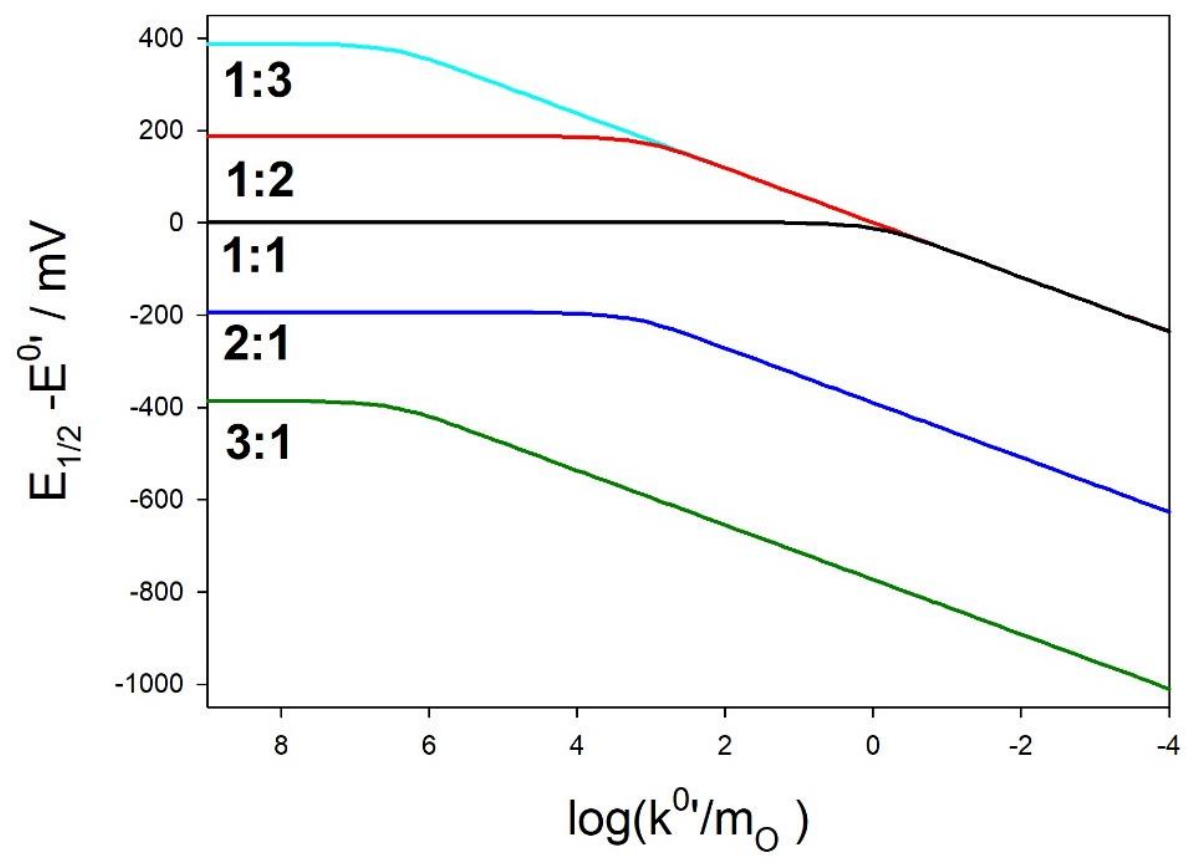

Figure 4. Variation of the half wave potential of the stationary current-potential curves with $\log \left(k^{0^{\prime}} / m_{\mathrm{O}}\right)$ for different reaction orders (indicated on the curves). $\alpha=0.5, n=2$. 

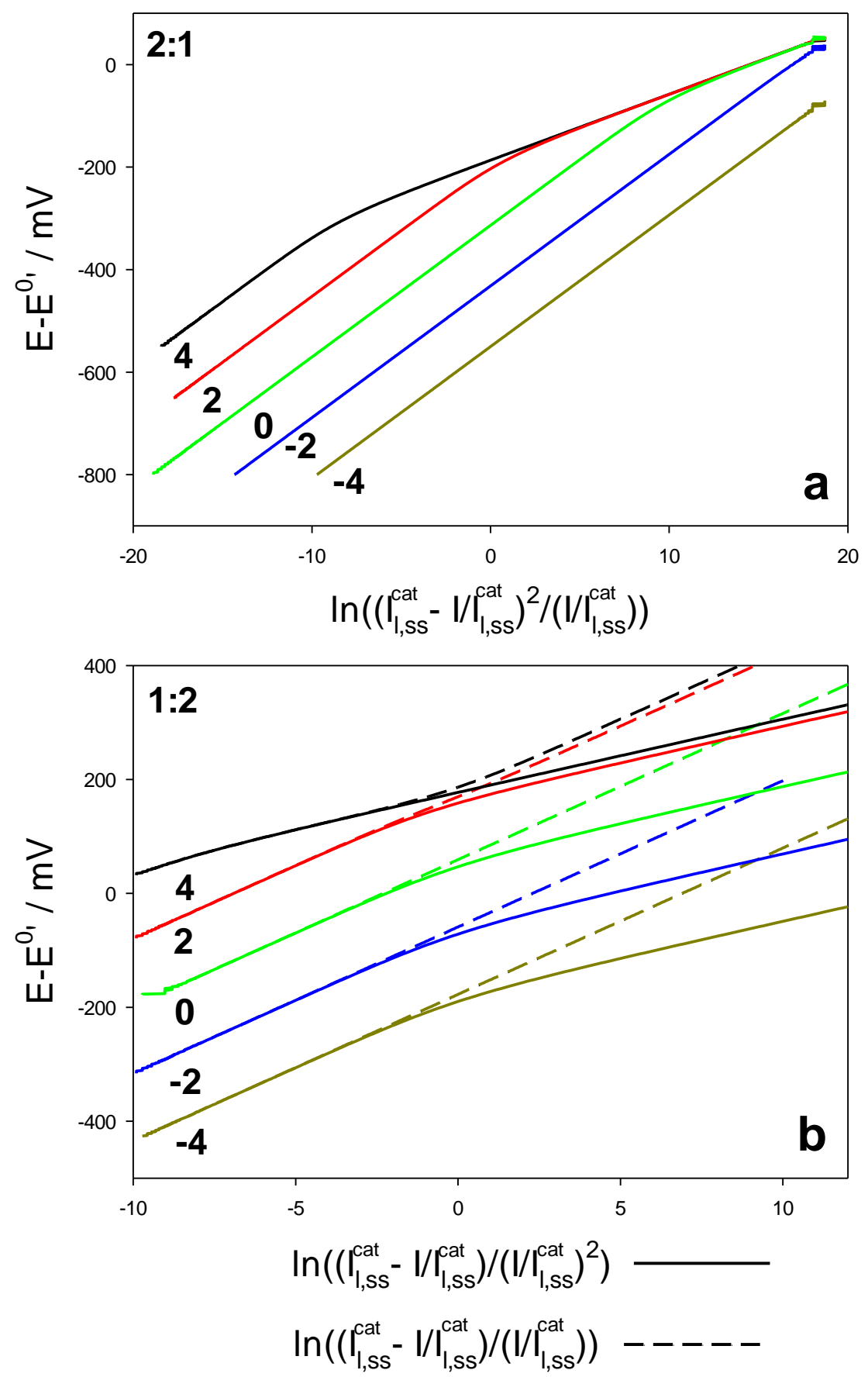

Figure 5. (a) $\left(E-E^{0^{\prime}}\right) \quad v s \ln \left(\left(\left(I_{1, \mathrm{ss}}^{\mathrm{cat}}-I\right) / I_{1, \mathrm{ss}}^{\mathrm{cat}}\right)^{v_{\mathrm{O}}} /\left(I / I_{1, \mathrm{ss}}^{\mathrm{cat}}\right)^{v_{\mathrm{R}}}\right)$ curves of case $2: 1$ and (b) $\left(E-E^{0^{\prime}}\right) \quad v s \quad \ln \left(\left(\left(I_{1, \mathrm{ss}}^{\mathrm{cat}}-I\right) / I_{1, \mathrm{ss}}^{\mathrm{cat}}\right)^{v_{\mathrm{O}}} /\left(I / I_{1, \mathrm{ss}}^{\mathrm{cat}}\right)^{v_{\mathrm{R}}}\right)$ curves (solid lines) and $\left(E-E^{0^{\prime}}\right) \quad v s$ $\ln \left(\left(\left(I_{1, \mathrm{ss}}^{\mathrm{cat}}-I\right) / I_{1, \mathrm{ss}}^{\mathrm{cat}}\right)^{v_{\mathrm{O}}} /\left(I / I_{1, \mathrm{ss}}^{\mathrm{cat}}\right)\right)$ curves (dashed lines) of case 1:2. Calculated from Eq. (28) for different values of $\log \left(k^{0^{\prime}} / \mathrm{cm} \mathrm{s}^{-1}\right)$ (indicated on the curves). $m_{\mathrm{O}}=m_{\mathrm{R}}=0.1 \mathrm{~cm} \mathrm{~s}^{-1}, c_{\mathrm{O}}^{*}=10^{-3}$ M. 

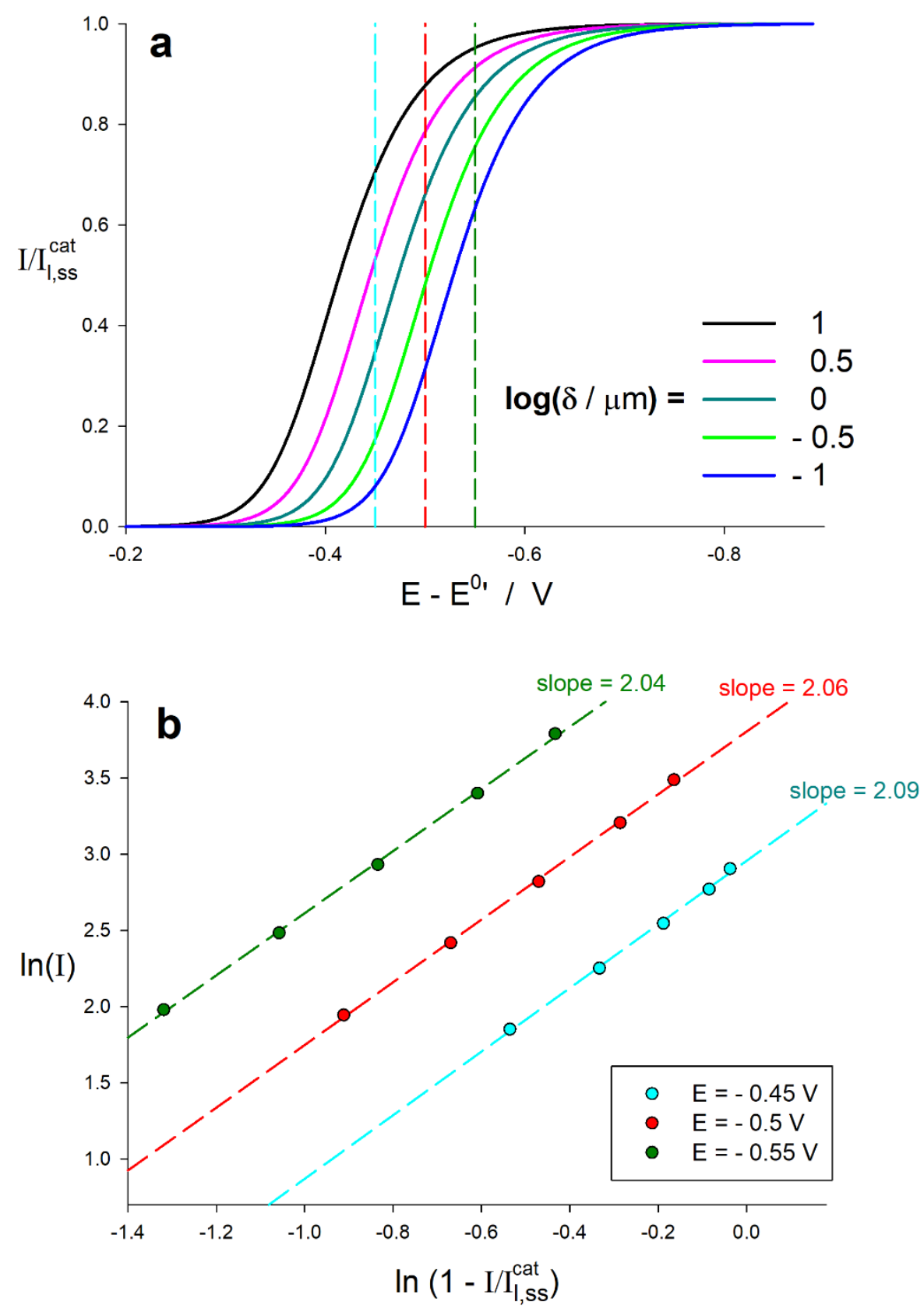

Figure 6. (a) $\left(I / I_{1, \mathrm{ss}}^{\mathrm{cat}}\right)-\left(E-E^{0^{\prime}}\right)$ curves for case $2: 1$ with $k^{0^{\prime}}=10^{-6} \mathrm{~cm} \mathrm{~s}^{-1}$, calculated from Eqn. (28) and different values of $\log (\delta / \mu \mathrm{m})$ (indicated on the graph). (b) Generalized KouteckýLevich analysis of the stationary response in figure $6 \mathrm{a}$ for three different values of the applied potential (indicated on the graph). $\alpha=0.5, n=2, D_{\mathrm{O}}=D_{\mathrm{R}}=10^{-5} \mathrm{~cm}^{2} \mathrm{~s}^{-1}, c_{\mathrm{O}}^{*}=10^{-3} \mathrm{M}$. 


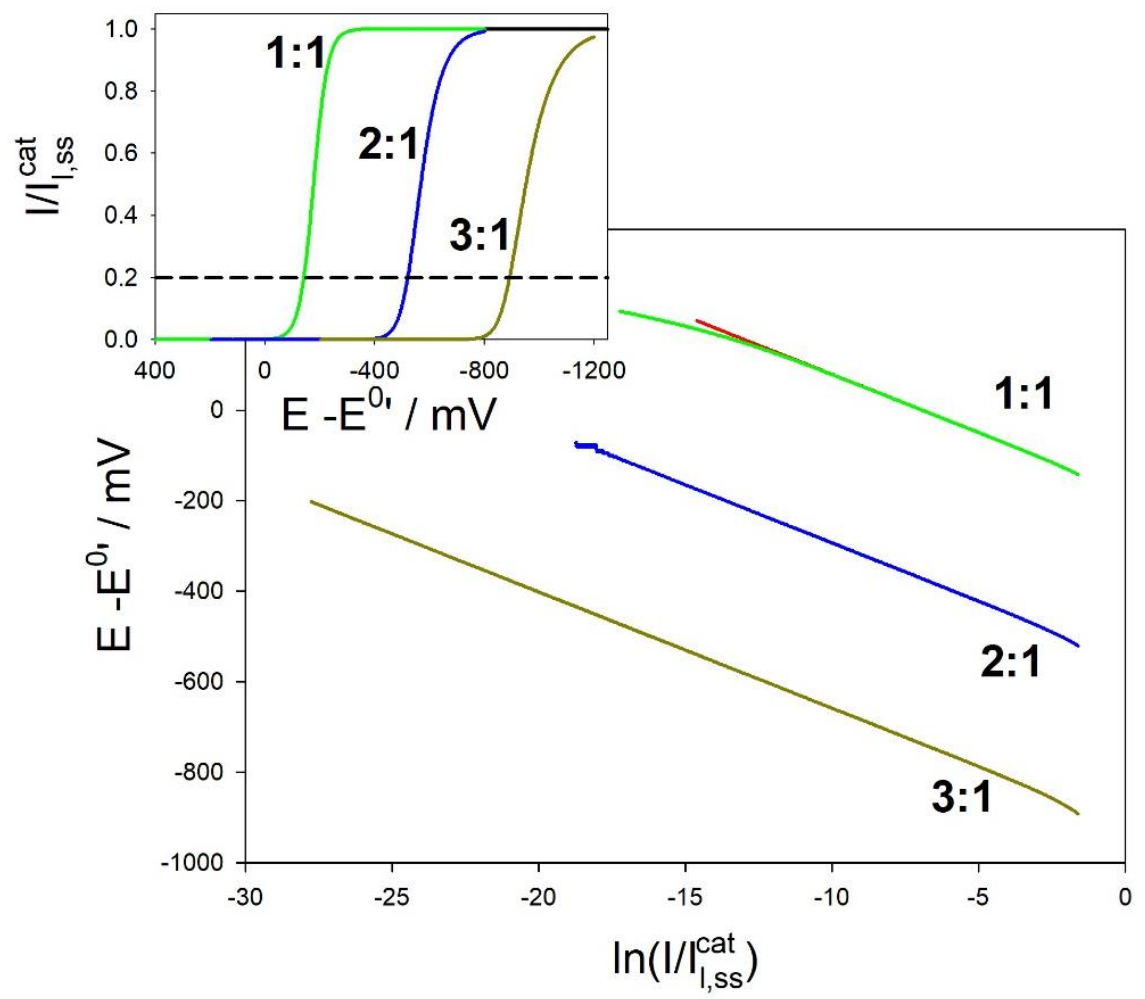

Figure 7. Tafel analysis of the stationary current-potential curves calculated from Eqn. (28) for cases 1:1, 2:1, 2:1, 1:3 and 3:1 (see Inset) corresponding to $\delta_{\mathrm{O}}=\delta_{\mathrm{R}}=1 \mu \mathrm{m}$ and $D_{\mathrm{O}}=D_{\mathrm{R}}=10^{-5}$ $\mathrm{cm}^{2} \mathrm{~s}^{-1}$, calculated for different values of the rate constant shown in the curves. $c_{\mathrm{O}}^{*}=10^{-3} \mathrm{M}$. $\log \left(k^{0^{\prime}}\right)=-4, \alpha=0.5$. Dashed line in the inset indicates the limit of the foot of the cathodic waves. 

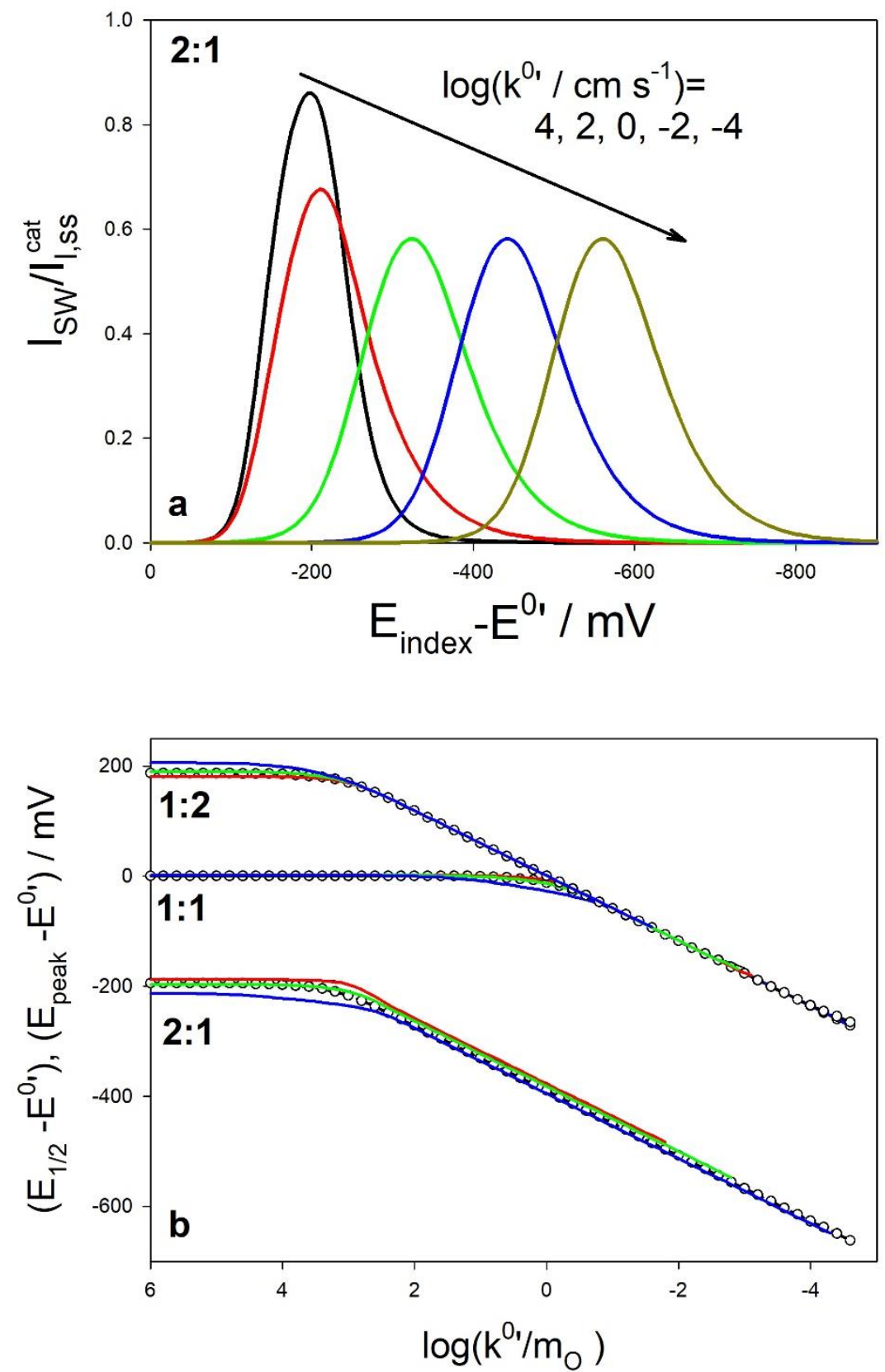

Figure 8. (a) $\left(I_{\mathrm{sw}} / I_{1, \mathrm{ss}}^{\mathrm{cat}}\right)-\left(E-E^{0^{\prime}}\right)$ curves calculated from Eqn. (28) for the cases 1:1, 2:1 and 3:1 with $\delta_{\mathrm{O}}=\delta_{\mathrm{R}}=1 \mu \mathrm{m}$ and $D_{\mathrm{O}}=D_{\mathrm{R}}=10^{-5} \mathrm{~cm}^{2} \mathrm{~s}^{-1}$, calculated for different values of the rate constant (values of $\log \left(k^{0^{\prime}} / \mathrm{cm} \mathrm{s}^{-1}\right)$ shown on the curves). $c_{\mathrm{O}}^{*}=10^{-3} \mathrm{M}, E_{\mathrm{SW}}=50 \mathrm{mV}$. (b) Variation of $E_{1 / 2}-\mathrm{E}^{0}$, (symbols) and $E_{\text {peak }}-\mathrm{E}^{0}$, (lines) with $\log \left(k^{0^{\prime}} / m_{\mathrm{O}}\right)$. The values of $E_{\text {peak }}$ have been obtained in square wave voltammetry with $E_{\mathrm{Sw}}=10 \mathrm{mV}$ (red lines), $50 \mathrm{mV}$ (green lines) and $100 \mathrm{mV}$ (blue lines). The same responses would be obtained with differential staircase voltammetry or differential pulse voltammetry for equivalent pulse amplitudes (i.e., $\Delta E=2 E_{\mathrm{Sw}}$ ). Potential step = $5 \mathrm{mV}$, 


\section{References}

[1] W. Chen, M. Le Xu, M.F. Li, Z. Wei, J. Cai, Y.X. Chen, Quantifying intrinsic kinetics of electrochemical reaction controlled by mass transfer of multiple species under rotating disk electrode configuration, J. Electroanal. Chem. 872 (2020) 114042. doi:10.1016/j.jelechem.2020.114042.

[2] S. Picart, E. Geniès, Electrochemical study of 2,5-dimercapto-1,3,4-thiadiazole in acetonitrile, J. Electroanal. Chem. 408 (1996) 53-60. doi:10.1016/0022-0728(95)044604.

[3] H. Chen, A. Kaliyaraj Selva Kumar, H. Le, R.G. Compton, Non-unity stoichiometric reversible electrode reactions. The effect of coupled kinetics and the oxidation of bromide, J. Electroanal. Chem. 876 (2020) 114730. doi:10.1016/j.jelechem.2020.114730.

[4] H. Wei, H. Wang, H. Tang, Y. Li, Voltammetric Analysis of Single Nanobubble Formation on Ag and Ag@MoS2 Nanoelectrodes, J. Phys. Chem. C. acs.jpcc.0 (2021).

[5] O. V. Klymenko, R.G. Compton, Mass transport corrected Tafel analysis for electrochemically reversible systems of complex stoichiometry, J. Electroanal. Chem. 571 (2004) 207-210. doi:10.1016/j.jelechem.2004.05.011.

[6] M.S. Shuman, Nonunity Electrode Reaction Orders and Stationary Electrode Polarography, Anal. Chem. 41 (1969) 142-146. doi:10.1021/ac60270a014.

[7] X. Jiao, C. Batchelor-Mcauley, E. Kätelhön, J. Ellison, K. Tschulik, R.G. Compton, The subtleties of the reversible hydrogen evolution reaction arising from the nonunity stoichiometry, J. Phys. Chem. C. 119 (2015) 9402-9410. doi:10.1021/acs.jpcc.5b01864.

[8] A. Jaworski, M. Donten, Z. Stojek, J.G. Osteryoung, Conditions of strict voltammetric reversibility of the H+/H2 couple at platinum electrodes, Anal. Chem. 71 (1999) 243-246. doi:10.1021/ac9804240.

[9] J.M. Gómez-Gil, E. Laborda, A. Molina, General Explicit Mathematical Solution for the Voltammetry of Nonunity Stoichiometry Electrode Reactions: Diagnosis Criteria in Cyclic Voltammetry, Anal. Chem. $92 \quad$ (2020) 3728-3734. doi:10.1021/acs.analchem.9b05023.

[10] R. Parsons, Electrochemical nomenclature, Pure Appl. Chem. (2008). doi:10.1351/pac197437040499.

[11] E. Laborda, J. González, F. Martínez-Ortiz, A. Molina, Voltammetry at microelectrodes of reversible electrode reactions with complex stoichiometry: A general analytical theoretical framework, J. Electroanal. Chem. $872 \quad$ (2020) 113932. doi:10.1016/j.jelechem.2020.113932.

[12] T. V. Kármán, Über laminare und turbulente Reibung, ZAMM - J. Appl. Math. Mech. / Zeitschrift Für Angew. Math. Und Mech. 1 (1921) 233-252. doi:10.1002/zamm.19210010401. 
[13] A.J. Bard, L.R. Faulkner, Electrochemical Methods. Fundamentals and Applications, John Wiley \& Sons, Inc., New York, 2001.

[14] A. Molina, J. Gonzalez, E.O. Barnes, R.G. Compton, Simple analytical equations for the current-potential curves at microelectrodes: A universal approach, J. Phys. Chem. C. 118 (2014) 346-356.

[15] A. Molina, J. González, Pulse Voltammetry in Physical Electrochemistry and Electroanalysis, Springer International Publishing, Berlin, 2016. doi:10.1007/978-3-31921251-7.

[16] J. Gálvez, J. Albadalejo, Á. Molina, Polarografía DC: Curvas corriente-potencial de procesos de electrodo con órdenes de reacción electroquímicos diferentes de la unidad, An. Química. 83 (1987) 577-585.

[17] Y. Uchida, E. Kätelhön, R.G. Compton, Linear sweep voltammetry with non-triangular waveforms: New opportunities in electroanalysis, J. Electroanal. Chem. 818 (2018) 140148. doi:10.1016/j.jelechem.2018.04.028.

[18] Y. Uchida, E. Kätelhön, R.G. Compton, Sweep voltammetry with a semi-circular potential waveform: Electrode kinetics, J. Electroanal. Chem. 835 (2019) 60-66. doi:10.1016/j.jelechem.2018.12.030.

[19] F. Martínez-Ortiz, N. Zoroa, Á. Molina, C. Serna, E. Laborda, Electrochemical digital simulations with an exponentially expanding grid: General expressions for higher order approximations to spatial derivatives: The special case of four-point formulas and their application to multipulse techniques in planar and any, Electrochim. Acta. 54 (2009) $1042-1055$. 